\title{
Qual o papel da imanência na reflexão linguística e semiológica de Saussure?*
}

\author{
What is the role of immanence in Saussure's linguistic and semiological reflection?
}

Michel Arrivé

Université de Paris Ouest - Nanterre - França

\begin{abstract}
$\diamond$
Resumo: O problema da imanência oposta à transcendência se apresenta em Saussure de modo completamente diverso do de Hjelmslev, que exibe uma tendência mais formalista em suas formulações. Nenhum dos dois termos é utilizado de hábito por Saussure. Não se poderia dizer que ele nunca os usa, já que é imprudente formular um juízo de ausência sobre um elemento de um texto. Mas os índices do CLG, dos Escritos de Linguística Geral (2002) e da Science du langage não trazem à primeira vista nenhum dos dois termos. A ausência das palavras não implica a ausência do problema. Este trabalho discute, a partir de textos recentes de Saussure, o papel do conceito de imanência em sua reflexão, comparando esta última com a de Hjelmslev.
\end{abstract}

Palavras-chave: Saussure; Imanência; Hjesmslev

\begin{abstract}
The problem of immanence as opposed to transcendence is present in Saussure's writings in a very different way from that of Hjelmslev, which is more formalist in his writings. None of these terms are usually used by Saussure. One cannot say he never uses them, for it is risky to talk about absence regarding a part of a text. But the indexes of $C L G$-Course of General Linguistics (2002) and that of Science du langage (Science of Language) do not bring them at first sight. But the absence of the words do not imply the absence of the problem. This paper discusses, considering some Saussurian texts, the role of the concept of immanence in his reflection, comparing this latter to that of Hjelmslev.
\end{abstract}

Keywords: Saussure; Immanence; Hjelmslev

Antes de formular a questão que dá título a este artigo, é sem dúvida útil atribuir-lhe uma maior extensão. É preciso enunciá-la de modo geral sob a forma: a linguagem pertence ao domínio da imanência ou da transcendência? Deveríamos então interrogar os filósofos, o que não é nada fácil. Grande número deles toma a linguagem apenas como o instrumento de designação e de comunicação que - tão imperfeita quanto se mostra

\footnotetext{
* Tradução de Adail Sobral (UCPel) de um original inédito enviado pelo autor. $\mathrm{O}$ tradutor gostaria de agradecer ao autor a cessão do texto para tradução. O texto traz alguns aspectos da reflexão saussuriana que enriquecem os atuais estudos sobre o fundador da linguística, contribuindo para refutar ou ao menos para abalar certas alegações feitas sem muito rigor, a par de levantar algumas relevantes questões para a reflexão linguística. $\mathrm{O}$ tradutor seguiu os textos originais citados pelo autor, e os traduziu, mesmo quando o texto foi o do CLG. Isso se deveu à necessidade de respeitar a argumentação do autor, que partiu dos originais citados.
}

dessa dupla perspectiva - ela, contudo, de fato é. É assim que procede, entre grande quantidade de outros - que sem dúvida se distinguem entre si em aspectos não negligenciáveis -, o Spinoza dos Pensamentos Metafísicos: a análise dos termos Verdadeiro e Falso permite-lhe dizer que essas palavras - como muitas outras - não são senão "denominações extrínsecas das coisas". Por essa razão, sua atribuição às coisas só pode ser uma ação do "retor" (1954, p. 317). Essa propriedade exclui o Verdadeiro da classe dos "termos transcendentais" (1954, p. 318), proposição em que o adjetivo transcendental tem um sentido muito diferente daquele que lhe será dado, por exemplo, por Hjelmslev. Afastada desse modo, por alguns de seus elementos, da transcendência, a linguagem, segundo Spinoza, não parece pertencer tampouco ao domínio da imanência. Para ele, ela se divide em dois tipos de elementos: os "termos transcendentais" - empregados 
pelos filósofos - e os outros, por exemplo, verdadeiro e falso, que "significam para o vulgo" (1954, p. 317).

Como muitos pensadores que têm uma atitude desse tipo com relação à linguagem, Spinoza manifesta interesse - e competência - pela história dos fenômenos linguísticos: logo depois da análise dos termos verdadeiro e falso, faz a história, bastante pitoresca, de sua evolução semântica (1954, p.317). A consideração destacada, em todo o discurso, da linguagem e das línguas, dos dados relativos ao sujeito falante e à mudança é, antes de tudo, um indício não enganoso de uma concepção não imanentista.

No entanto, é mais prudente e mais útil abandonar os filósofos e perguntar aos próprios linguistas acerca da imanência da linguagem. O linguista que elaborou a questão da maneira mais explícita foi sem dúvida Hjelmslev.

Nos Prolegômenos a uma Teoria da Linguagem, Hjelmslev não dá nenhuma definição prévia da noção de imanência. Em vão procuramos o termo na lista das "Definições" que encerra a obra (1971, p. 164-169; 1993, p. 131-138). Mas o primeiro capítulo do livro é dedicado a acentuar a necessidade absoluta de construir a "teoria da linguagem" de um modo totalmente "imanente" (1971, p. 13; 1993, p. 8). A enumeração dos traços contabilizados para atender a essa exigência permitirá determinar a concepção que o autor elabora sobre a noção.

A "teoria da linguagem", que tem um "objetivo exclusivamente imanente", opõe-se ao "estudo da linguagem", cujo objetivo é "essencialmente transcendente" (1971, p. 13; 1993, p. 8). A rejeição da transcendência não é, porém, nem absoluta, nem definitiva: a "Perspectiva Final", que constitui o último capítulo dos Prolegômenos, procede a uma recuperação, na verdade um pouco incômoda, da transcendência (1971, p. 160). "Fundada na imanência", a transcendência permanece de qualquer modo hierarquicamente mais importante que aquela.

Os traços que, segundo Hjelmslev, caracterizam a "teoria", para ele necessariamente "imanente", da linguagem se distribuem em dois modos complementares de abordagem.

No que se refere à finalidade, "o conhecimento imanente da língua" procura atingir "a língua enquanto estrutura específica que não se funda senão sobre si mesma" (1971, p. 31; 1993, p. 19). Trata-se ao mesmo tempo do esboço da definição hjelmsleviana da imanência e do ponto de partida da concepção da língua elaborada desde o capítulo 2, "Teoria da linguagem e humanismo": seu caráter "imanente" se relaciona com o fato de que ela "não se funda senão sobre si mesma". O teórico deve, portanto, descobrir "uma constância (konstanz) que não esteja enraizada numa 'realidade' (virkelighed) extralinguística; uma constância que faça que toda língua seja linguagem, seja que língua for, e que uma língua permaneça idêntica a si mesma por meio de suas manifestações mais diversas" (1971, p. 15; 1993, p.9). A que ordem pertencem as "diversidades" assim alegadas? O texto não o revela de imediato. Mas, a partir da página seguinte o autor se dedica a uma severa crítica da "história" (historien), tanto em seu domínio próprio como no das ciências humanas. É verossímil, pois, que as "manifestações mais diversas" englobem, entre várias outras (dialetais, sociais, até "individuais", como é dito na p.16), as variações históricas que afetam as línguas. Assim, Hjelmslev parece afirmar que a identidade da língua consigo mesma se mantém segundo a "constância" que faz dela uma língua a despeito das transformações que aparentemente a modificam. Será que a imanência implica necessariamente a permanência? Embora não seja formulada explicitamente, essa proposição é pressuposta pela maneira como o problema é abordado. Voltaremos ao assunto.

Depois da finalidade vem o exame dos métodos a usar para chegar à teoria imanente da linguagem. $\mathrm{O}$ "ponto de vista" (synspunkt) imanentista consiste em proceder à eliminação de toda "realidade extralinguística". Seguese a exclusão das duas "realidades" que costumam ser levadas em conta pelas abordagens "transcendentes". Trata-se, por um lado, "da descrição física e fisiológica dos sons da linguagem" e, por outro, "da descrição psicológica e lógica dos signos - isto é, das palavras e das frases" (1971, p. 10-11; 1993, p.6). As justificativas dessas duas exclusões são exatamente paralelas.

A primeira descrição, a dos sons, é afastada porque "pode recair na física e na fisiologia puras". Isso porque os sons não são a única manifestação possível para as línguas. Alguns longos desenvolvimentos dos Prolegômenos (1971, p.131-134; 92-94) enumeram diversas manifestações substanciais efetivas ou possíveis das "línguas naturais" (no singular: dagligsproget, cuja melhor tradução é sem dúvida "língua cotidiana"): gestualidade, escrita, "códigos signaléticos das armadas navais, alfabetos dos surdos-mudos"2. A conclusão é coerente: "Um sistema de expressão linguística, seja qual for, pode manifestar-se por meio de substâncias de expressão extremamente diferentes" (1991, p.133; 1993, p. 93).

\footnotetext{
O dinamarquês sprog (sproget com o artigo posposto), assim como o alemão Sprache e o inglês language, não marca a oposição manifestada nas línguas românicas pelos pares como langue/langage, lengua/ lenguaje, lingua/linguagio etc. Só o contexto permite marcar a diferença de sentido. A dúvida entre as duas interpretações às vezes continua possível.

2 O parentesco dessas proposições, em especial quando incidem na escrita, com textos saussurianos que Hjelmslev, em sua época, não podia evidentemente conhecer, é flagrante. Ver, por exemplo, Saussure, 2011, p. 135.
} 
Os sons em sua realidade substancial, acústica e articulatória, não têm portanto nenhuma pertinência com relação ao sistema da língua.

A segunda descrição afastada correria o risco de "reduzir-se a uma psicologia, a uma lógica e a uma ontologia puras" e de "perder de vista, desse modo, seu ponto de partida linguístico". O "aspecto psicológico e lógico dos signos - palavras e frases" (tegnenes - ordenes og soetingernes, 1993, p.6) - deve ser rigorosamente separado do "conteúdo" (inhold 1993, p.44-55). Este último é, com efeito, definido de maneira "puramente operacional e formal" como um dos dois "funtivos" que "contraem a função semiótica" (tegnfunktion), estabelecida entre o "conteúdo" e a "expressão" (udtryk): "um conteúdo só é conteúdo por ser conteúdo de uma expressão" (1971, p.67). Tanto o conteúdo como a expressão, cada um naquilo que lhe diz respeito, se distinguem de seus "sentidos" (mening) respectivos: "sentido [substância] do conteúdo" (inholdsmening) e "sentido [substância] da expressão" (udtryksmening) (1993, p. 45). ${ }^{3}$ Para o conteúdo, o sentido [substância] é constituído pelos "aspectos psicológicos e lógicos" do texto. É precisamente esse "sentido" [substância] que é, em termos "provisórios", eliminado.

Essas análises, como vimos, devem enfrentar um problema fundamental: o das transformações da língua, em especial no tempo, uma vez que a língua, como é dito no capítulo 2, é dada como "idêntica a si mesma". De que maneira essa "identidade a si mesma da língua" resiste à diversidade, sem nenhuma dúvida reconhecida, de "suas manifestações mais diversas", notadamente históricas? Pois as mudanças que a afetam - ou parecem afetá-la - podem de resto vir de além dela mesma e, com isso, opor-se a uma concepção pura e totalmente imanentista. É fundamental, por conseguinte, em todo estudo imanentista da linguagem, dar uma solução a esse problema.

Hjelmslev não nega as modificações que a história traz de forma inevitável a toda língua. Não obstante, sua atitude com relação à mudança linguística apresenta uma especificidade, assinalada por um fenômeno revelador: ele não retoma a dicotomia saussuriana de sincronia e diacronia. Salvo erro ou esquecimento, nenhum dos dois termos aparece como tal em A Linguagem nem nos Prolegômenos, ${ }^{4}$ não sendo indicados nem nas "Definições" dos Prolegômenos nem sequer nos índices

\footnotetext{
3 Hjelmslev afirma que nada impede de recorrer à noção de "sentido [substância] da expressão", embora isso seja contrário ao hábito" (1971, p. 74).

4 Os dois adjetivos diacrônico e sincrônico (em dinamarquês diakroniske e synkroniske) aparecem porém: o primeiro ao menos duas vezes, o segundo ao menos uma vez, nos Prolegômenos (1971, p.133, 1993, p.93). Os dois adjetivos fazem referência não à mudança linguística, mas ao problema da instituição do alfabeto. p. 16 de 1971, diacrônico traduzido historisk (1993, p. 10)
}

das duas obras. Hjelmslev não aborda explicitamente o problema da mudança a não ser quanto às espécies da mudança "puramente fonética" e da "mudança semântica": ambas podem intervir "sem que o esquema linguístico seja afetado em absoluto" (1971, p.134; 1993, p. 93-94). Trata-se da implicação inevitável da exterioridade previamente formulada dos aspectos "puramente fonéticos" e "puramente semânticos". É verdade que aparece em seguida uma alusão à distinção entre essas mudanças exteriores, transcendentes, e as "mudanças formais", imanentes. Enquanto tais, estas afetariam o esquema linguístico. Mas não são mais mencionadas na sequência dos Prolegômenos.

É em A Linguagem que aparece de modo completo a concepção hjelmsleviana da "transformação da linguagem". Hjelmslev procede nesse texto a uma mudança decisiva do conceito. Elaborada em primeiro lugar na forma de uma interrogação retórica (1966, p. 169), ela não tarda a assumir a forma assertiva que se esperava, na forma de uma comparação - de origem saussuriana - com a prática do jogo de xadrez:

Na vigência da lei, todo $p$ no início de palavra é mecanicamente transformado num $f$ [na língua fictícia tomada aqui como exemplo]; trata-se de uma lei de conversão do mesmo tipo da que vale para o jogo de xadrez: os peões que atingem o outro lado do tabuleiro têm seu valor transformado no de rainha. Essa 'transformação' se produz, ou pode produzir-se, sempre que se joga xadrez, seja amanhã ou no próximo ano; não se trata de uma modificação, mas de um estado. (1966, p. 169)

A "modificação", comprometida de maneira inevitável com a temporalidade, acha-se reenviada à aplicação, sempre instantânea, de uma lei constantemente presente e imperativa. Instantânea? Melhor dizendo: intemporal; ela se situa "amanhã ou no próximo ano". O tempo não importa. Cabe apenas à língua a lei que impõe a conversão. A língua conserva, pois, intacta, sua identidade consigo mesma.

No entanto, a dúvida subsiste. Manifesta-se em primeiro lugar por uma avaliação quantitativa: "Muitos fenômenos que foram considerados exclusivamente do ponto de vista da transformação linguística não passam de fenômenos estáticos" (1966, p. 169-170).

"Muitos"? Sim, muitos. Mas não todos. Alguns fenômenos resistem à análise puramente estática da transformação. Hjelmslev observa-o, quase lamentando isso: "permanece [sublinhado por MA] o fato de que a língua se transforma" (1966, p. 170). Essa transformação vem das "mudanças da pronúncia" e "daquelas da significação e dos signos" (1966, p. 171). Como dar conta desse resíduo? O único meio é remetê-lo do "esquema", 
no qual nada tem a fazer, ao "uso". Será então "o homem" que estará em causa: "O homem é um ser caprichoso e enigmático, e é ele que está em jogo aqui” (1966, p. 171).

Hjelmslev atribui "as transformações fonéticas que uma língua sofre no decorrer do tempo" a "algumas tendências predominantes que uma mesma população pode conservar durante vários séculos" (1966, p. 171). Ele continua, porém, a observar que "as transformações da estrutura não podem residir nas tendências da comunidade linguística pois a estrutura é justamente definida como alguma coisa que é independente delas" (ibid.).

Seria sem dúvida justo perguntar, com uma surda inquietação, qual o papel do "homem" na reflexão de Hjelmslev. O homem "que está em jogo aqui" é, inevitavelmente, o sujeito falante. Qual a conotação dos adjetivos "caprichoso" e "enigmático" que lhe são atribuídos? Laudatória ou pejorativa? Presente, no mais alto grau, no "uso", o homem acaso não está, de outro modo, é verdade, no "esquema"? E a "comunidade linguística" em que ele se insere? Amplas questões que, por ora, me contento em evocar, porque Saussure nos permitirá voltar a elas.

Hjelmslev costuma invariavelmente mostrar um rigor extremo na apreciação dos trabalhos de seus predecessores com relação a seus próprios pontos de vista. Assim, ele rejeita como "transcendentais" as formulações de "sistemas de axiomas" de Bloomfield e de Bühler (1971, p. 13). Por fim, reconhece no modo de abordagem que usa "um único antecessor indiscutível: o suíço Ferdinand de Saussure" (1971, p. 14). Ele emite contudo algumas reservas. Além da exclusão, não explicitamente reivindicada, da sincronia e da diacronia, Hjelmslev formula também duas críticas severas. A primeira se baseia na maneira pela qual o $C L G$ apresenta as relações entre forma e substância (1971, p.67-68). A segunda se refere à "base essencialmente sociológica e psicológica" na qual Saussure fundamenta a linguística (1971, p. 136).

A esta altura, ouço uma tímida questão de meus leitores: por que afinal falamos de Spinoza e de Hjelmslev se o título anuncia apenas Saussure? A resposta é fácil. Spinoza, entre muitos outros, mas de uma forma particularmente acentuada, dá o exemplo de uma reflexão sobre a linguagem afastada ao extremo de todo ponto de vista imanentista. Ocorre o contrário com Hjelmslev: é sem dúvida impossível formular uma concepção da linguagem mais imanentista que a dele. No que se refere a essas duas concepções opostas, a posição de Saussure poderá ser avaliada em sua justa medida.

$$
* * *
$$

O problema da imanência oposta à transcendência se apresenta em Saussure de modo completamente diverso do de Hjelmslev. Nenhum dos dois termos é utilizado de hábito por Saussure. Não ouso dizer nunca, já que é imprudente formular um juízo de ausência sobre um elemento de um texto. Mas os índices do $C L G$, dos Escritos de Linguística Geral (2002) e da Science du langage não trazem à primeira vista nenhum dos dois termos.

A ausência das palavras não implica a ausência do problema. É certo que Saussure recusa explicitamente, por várias vezes, o estatuto de filósofo ou de metafísico: "Estamos bem longe de querer fazer metafísica aqui", insinua, de maneira furtiva, a propósito do problema da presença na consciência da palavra e de seu sentido (2011, p. 111; ver também 106). Esse gesto de negação costuma sobrevir quando o autor se dá conta de que sua reflexão, exterior, em sua origem, ao campo da metafísica, se compromete com ele irremediavelmente. Saussure aceita às vezes esse engajamento e chega a enfatizar a importância "filosófica" de um problema que aborda. É isso o que ocorre a propósito da mudança linguística, estreitamente ligada à questão da imanência. Formulando-o como "fortuito", ele enuncia a seguinte proposição: "Essa visão, que nos é inspirada pela linguística histórica, é desconhecida pela gramática tradicional [...]. A maioria dos filósofos da língua também a ignora; e, contudo, nada há de mais importante da perspectiva filosófica"5 $(C L G$, p. 122).

Sem mostrar-se ostensivamente, as preocupações "filosóficas" estão presentes em Saussure. A imanência não precisa ser nomeada por ser o objeto frequente constante, diria eu - de seu interesse. Ela se manifesta sob vários aspectos.

Descrever a língua de forma imanente é, em primeiro lugar, defini-la por si mesma, independentemente de todo objeto que lhe seja exterior. Esse gesto é realizado por Saussure de diferentes modos, necessariamente articulados entre si de tal maneira que é possível fazê-los aparecer numa ordem indiferente. Esse é o partido que Saussure resolve tomar no momento em que se pergunta, angustiado: "Unde exoriar?":

Unde exoriar? - Eis a questão pouco pretensiosa, e até terrivelmente positiva e modesta, que se pode formular antes de tentar abordar, por algum ponto, a escorregadia substância da língua. Se o que desejo dizer acerca disso é verdadeiro, não há um único ponto que constitua um evidente ponto de partida. (2002, p. 281)

Submeter "a escorregadia substância da língua" a um ponto de vista imanentista é, em primeiro lugar,

\footnotetext{
5 Cito o $C L G$, seguindo aqui o exemplo de Hjelmslev, que, a bem da verdade, não podia fazer outra coisa em sua época. Nesse ponto, a fidelidade quase literal do texto é garantida por suas fontes manuscritas. Ver, por exemplo, SOFIA, 2014, p. 361.
} 
defini-la, de modo inverso, como uma forma, concebida como interna, afastando o recurso às substâncias externas. A reivindicação dessa posição é rigorosa, explícita e repetitiva, mesmo que se manifeste com mais energia nos propósitos didáticos do $C L G$ que nas meditações silenciosas de Science du langage. Por conseguinte, é o texto do $C L G$ que convém recordar:

A língua elabora suas unidades ao se constituir entre duas massas amorfas. [...] A linguística trabalha, portanto, no terreno limítrofe em que os elementos das duas ordens se combinam; essa combinação produz uma forma, não uma substância. (CLG, p. 156-157)

Uma forma, diz-nos ele. Resta expor a forma dessa "forma". É aqui que intervém a noção central de "sistemas de valores relativos e negativos, que não têm existência senão pelo efeito de sua oposição" (2011, p. 190), e o princípio, que lhe é inseparável, do "arbitrário do signo" (CLG, p. 100-102). Julgo inútil voltar, depois de tantos outros, ao laço que se estabelece entre esses dois aspectos da reflexão saussuriana. Observo, no entanto, que o arbitrário do signo tem por efeito eliminar toda relação da língua como sistema com alguma "realidade extralinguística", qualquer que seja. Saussure recorre à ficção de uma língua constituída por dois signos. Impedida por isso de encarregar-se de qualquer real, seja qual for, ela é, não obstante, própria a "tudo classificar":

Assim, numa língua composta no total por dois signos, $b a$ e la, a totalidade das percepções confusas do espírito virá NECESSARIAMENTE classificar-se ou sob $b a$ ou sob la: o espírito encontrará, pelo simples fato de existir uma diferença $b a / l a$ e de que não existe outra, um caráter distintivo que lhe permita regularmente classificar sob o primeiro ou sob o segundo tipo (por exemplo, a distinção entre sólido e não sólido). (2011, p. 187-188)

As exclusões que são necessárias à utilização desse ponto de vista imanentista incidem sobre os objetos igualmente eliminados por Hjelmslev. Trata-se, por um lado, da matéria sonora tal como se manifesta pela voz humana, e, por outro, daquilo que há de "psicologicamente puro" no sentido das unidades manifestas.

A primeira dessas exclusões é constante em Saussure. Ela se justifica em termos "filosóficos" desde 1894, nas Notes pour un article sur Whitney:

Num dos últimos capítulos de Life and Growth of Language, Whitney diz que os homens se serviram da voz como se teriam servido do gesto ou de outra coisa, porque lhes pareceu mais cômodo servir-se da voz. Avaliamos que essas duas linhas, que se assemelham a um grande paradoxo, [contribuem com] a mais justa ideia filosófica já dada da linguagem; mas, além disso, nossa prática mais cotidiana dos objetos submetidos a nossa análise teria tudo a ganhar a partir desse dado. (2002, p. 215; ver também GODEL, 1957, p. 193-1914; ENGLER, 1968-1989, p. 270)

Institui-se em outro ponto uma comparação bastante desagradável entre a voz humana e a prática do tingimento de tecidos que se impõe para o uso dos sinais marítimos coloridos: "O ato fonatório aparece como um instrumento necessário, mas, em si, muito menos essencial que, no caso dos sinais marítimos, a ação do tintureiro que preparou as bandeiras para dar a impressão do verde, do vermelho ou do preto" (2002, p. 248).

Segue-se a inevitável conclusão, que comporta a exclusão esperada: “As entidades da ordem vocal não são entidades linguísticas” (2002, p. 23).

A segunda exclusão não deve ser confundida com aquela que incide sobre a "coisa", como diz Saussure. Esta é constante, estando presente notadamente desde a definição do signo (CLG, p.97-98) e sempre que se menciona a "arbitrariedade do signo". A exclusão de que se fala aqui diz respeito ao sentido psicologicamente formado, que por isso se distingue do significado. A passagem mais pertinente a esse respeito é sem dúvida a de Sciences du langage, em que Saussure, num escrito de preparação do Segundo Curso de Linguística Geral, reúne as duas exclusões, que são, na maioria das vezes, examinadas de maneira separada. ${ }^{6}$ Mas, como se vê, de que forma dizer? Hesitar? Seria excessivo. Não: ele mostra sua perplexidade diante do rigor das exclusões a praticar, e o faz, ouso o oxímoro, por meio de seus silêncios, indicados em seu texto pelos espaços deixados em branco. Primeiramente, pelos sons: "Como para todo valor, natureza incorpórea do que constitui as unidades da língua. Não se trata da matéria fônica \{/substância vocal\} que [segmento deixado em branco]" (2011, p. 294).

$$
\text { E, aqui, pelas "ideias": }
$$

Mas, reciprocamente, se pode parecer paradoxal que o som seja algo de [segmento deixado em branco], é possível dizer outro tanto da ideia que se liga a uma palavra, que se liga às diferentes unidades. Ela também nunca representará senão um dos elementos do valor, e será uma ilusão julgar que, em nome desse elemento, se possa tratar pela psicologia pura as diferentes unidades da língua. (2011, p. 295)

Esses textos, revelados muito tardiamente, só podem ter permanecido desconhecidos por Hjelmslev.

\footnotetext{
6 Trata-se, por exemplo, do que se observa numa passagem de "De la double essence du language", na qual são sucessivamente rejeitadas como fora do "domínio linguístico" em primeiro lugar "as significações, as ideias, as categorias gramaticais exteriores aos signos", e, em seguida "as figuras vocais que servem de signos" (2011, p. 80).
} 
Evocam contudo de modo bastante direto, ao menos pelo conteúdo - uma vez que sua tonalidade se mostra muito diferente entre os dois autores -, as posições tomadas nos Prolegômenos acerca dos problemas evocados.

Seja como for, o resultado dessa dupla exclusão é a definição da língua como "sistema de valores", em termos saussuarianos, ou, em outros termos, como "estrutura específica que não se funda senão sobre si mesma". Isto é, qualquer que seja a designação, como objeto estritamente imanente.

No entanto, essa definição da língua como forma não deve ocultar uma outra definição. Ela se apresenta sob um aspecto diferente, menos espetacular e até bastante labiríntico, visto que expõe de modo simultâneo duas concepções aparentemente opostas da língua. Por esse fato, ela costuma ser ocultada. Além disso, é obscurecida por uma dificuldade lexical: o uso dos termos ideia e forma com sentidos capazes de levar o leitor a se perder:

A primeira expressão da realidade seria dizer que a língua (isto é, o sujeito falante) não percebe nem a ideia $a$, nem a forma $\mathrm{A}$, mas apenas a relação $a / \mathrm{A}$; essa expressão seria, por outro lado, inteiramente grosseira. $\mathrm{O}$ sujeito falante só percebe de fato a relação entre as duas relações $a / \mathrm{AHZ}$ e $a b c / \mathrm{A}$ ou $b / \mathrm{ARS} e b l r / \mathrm{B}$ etc. (SAUSSURE, 2011, p. 156; trata-se aparentemente de um texto preparatório ao Segundo Curso de Linguística Geral).

Procuremos orientar-nos nesse labirinto. A língua se funda na relação, ou, de maneira mais precisa, nas relações. Ela sem dúvida as "percebe", mas o motivo é que elas a constituem. Quais são elas, essas relações? Em primeiro lugar a que se estabelece entre $a$, "a ideia" - a compreender aqui como o primeiro aspecto da dificuldade anunciada, com o sentido que será mais tarde dado a significado -, e A, "a forma" - a compreender aqui como o segundo aspecto da dificuldade lexical, com o sentido que será mais tarde dado a significante. Mas ela é também e sobretudo "relação entre as duas relações $a / \mathrm{AHZ}$ e $a b c / \mathrm{A}$, ou $b / \mathrm{ARS}$ e $b l r / \mathrm{B}$ etc.", ou seja, entre o conjunto dos significantes e dos significados que a constituem no sistema de relações negativas que sua copresença faz surgir. Fundada em seu estatuto por um sistema de "relações de relações", a língua não cessa em absoluto, por conseguinte, de ser uma forma, desta vez no sentido de "sistema de valores relativos e negativos, não tendo existência senão pelo efeito de sua oposição" (2011, p. 190). Recupera-se, pois, o ponto de vista imanentista que foi até agora indicado.

Mas tudo já mudara, no labirinto do texto analisado, antes da utilização dessa concepção formalista, visto que a forma assim descrita como "relações de relações" acabava de ser identificada, no sentido mais literal do termo, a outro elemento: o sujeito falante - "a língua (isto é, o sujeito falante)". Ele substituiu a língua a ponto de dar a forma masculina ao pronome pessoal que supostamente a representa: Ele [em vez do esperado ela] não percebe de fato [...]" Retórica, essa identificação da língua com o sujeito falante? Sem dúvida. Ela manifesta, no entanto, o caráter inseparável desses dois objetos: um sistema formal e um sujeito humano. Não se trata de uma ocorrência isolada na reflexão saussuriana. Trata-se, ao contrário, de um elemento central de sua reflexão, ainda que muitas vezes ocultada. E temos outro testemunho: "A conquista destes últimos anos é ter por fim não apenas colocado tudo o que é a linguagem e a língua em seu verdadeiro lugar, exclusivamente o sujeito falante, seja como ser humano seja como ser social" (2011, p. 281).

Esse texto parece datar do início da estada de Saussure em Paris, em 1881. Ele marca, pois, a antiguidade em sua reflexão da consideração do sujeito falante, aqui reconhecido, em termos metafóricos, como "lugar" da língua e da linguagem. Concepção persistente, uma vez que o texto antes citado remonta sem dúvida aos anos 1909 e 1910. Com isso se avalia a distância que, acerca desse ponto, afasta Saussure das posições que, muito tempo depois, seriam retomadas por Hjelmslev.

No que se refere à imanência, vê-se surgir o problema: qual o papel da imanência se a língua é não só ela mesma como também o sujeito falante? Ela deixa de definir-se por si mesma e passa a fazê-lo por sua relação, qualquer que seja a sua forma, com uma outra instância. É preciso abandonar a imanência e falar de transcendência? E em que sentido se estabeleceria essa transcendência? Do sujeito à língua? Ou da língua ao sujeito? Contento-me em formular o problema.

Permanece o problema da evolução das línguas no tempo. Ele expõe desta vez, como vimos a propósito de Hjelmslev, a questão das relações entre imanência e permanência. $\mathrm{O}$ trajeto que é necessário seguir para abordá-lo é singularmente complexo, já que abrange de imediato uma bifurcação. O itinerário escolhido por Hjelmslev ignora, tanto quanto possível, aquele dos dois trajetos que leva em conta as mudanças linguísticas. Essa é a razão pela qual desaparece a distinção saussuriana entre sincronia e diacronia. Saussure segue um itinerário inteiramente diverso. Para elaborar a árdua metáfora, ele tenta seguir ao mesmo tempo os dois trajetos.

Num primeiro aspecto de sua reflexão, ele formula com efeito a "mudança" diacrônica como um caráter específico tanto da língua como de qualquer outro sistema de signos: "A língua se altera - ou, de preferência, evolui - sob a influência de todos os agentes que podem atingir quer os sons, quer os sentidos. Essa evolução é fatal; não há nenhum exemplo de uma língua que resista a ela" (CLG, p. 111). 
Um exemplo? O das mudanças fonéticas que afetaram o latim calidum, que se tornou chaud [quente] em francês e caldo em italiano:

Eis portanto um caso no qual é possível avaliar se a simples sucessão dos fenômenos fonéticos bastaria, como quase se tendeu por vezes a contestar, para criar algumas diferenças que vão até o ininteligível. É preciso afirmar que essa sucessão é absolutamente capaz, por si só, de transformar o aspecto de uma língua. (2011, p. 288)

"O aspecto", diz ele? Esse sistema acaso permanece intacto? O problema continua. Mas, de qualquer modo, a "inteligibilidade" é atingida. A propósito de outro sistema de signos, Saussure chega a excluir do campo da semiologia todo objeto que se não ache submetido à mudança diacrônica; é o caso, por exemplo, do texto literário. Bloqueado pelo nome do autor, ele escapa à "prova do tempo", não podendo por isso ser "comparado palavra por palavra", padrão de medida exemplar de todo objeto semiológico (1986, p. 193).

Assim, a língua e os outros sistemas de signos estão "fatalmente" submetidos aos efeitos transformadores do tempo: é ao menos isso que aparece nos textos citados. E em numerosos outros.

Observa-se porém em Saussure outro movimento de pensamento. Ele costuma manifestar-se por uma substituição lexical. O termo visado é mudança. Saussure o substitui por troca. Essa substituição aparece várias vezes na compilação Sciences du langage:

A troca, como única expressão verdadeira de todo movimento na língua. Há dois tipos de troca, que são inteiramente distintas na vida da língua, mas não há, em compensação, mudança, sendo necessário que houvesse uma matéria definida em si mesma num momento dado, o que nunca acontece; só se pronuncia uma palavra por seu valor. Na troca, a unidade é estabelecida por um valor ideal, em nome do qual se declaram adequados entre si objetos materiais que podem na verdade ser absolutamente dessemelhantes e, além disso, renovados sem cessar, cada um em sua substância. É exatamente o caráter de todas as "mudanças" ou "movimentos" linguísticos.

Não existe em absoluto outro princípio de unidade senão o da unidade de valor; por consequência, nenhuma mudança que não tenha a forma de uma troca". (2011, p. 165)

Essa eliminação da mudança em benefício da troca visa a excluir da teoria da linguagem a noção de transformação, diz-se no $C L G$, p. 225. Por quê? É que só a substância - por vezes também denominada "matéria" no texto de 2011 - é apropriada à transformação. A substituição de mudança ou transformação por troca não é nada mais que a marca de uma dupla operação negativa: dessubstancialização e destemporalização dos fenômenos linguísticos. Dessubstancialização? Em termos mais precisos, constatação repetida da nãosubstancialidade das unidades linguísticas. E, desse modo, de sua inaptidão à "transformação", ou seja, "mudança". Destemporalização? De forma mais exata, constatação do fato de que o tempo não é a causa das "trocas" que se tomam falsamente por "mudanças", mas que parecem modificar o "aspecto" da língua. A prova? Saussure volta a recorrer à linguística-ficção: "Se se tomasse a língua no tempo, sem a massa falante - suponhamos um indivíduo isolado que vivesse vários séculos - talvez não se constatasse nenhuma alteração: o tempo não agiria sobre ela" (CLG, p. 113).

O tempo não é a causa da "alteração". Segue-se a formulação da noção, aparentemente paradoxal, de "identidade diacrônica". É aquela que une calidum a chaud, que já foram acima qualificados de "diferentes" a ponto de serem "ininteligíveis":

A identidade diacrônica de duas palavras tão diferentes quanto calidum e chaud significa simplesmente que se passou de uma a outra através de uma série de identidades sincrônicas na fala, sem que nunca o laço que as une tenha sido rompido pelas transformações fonéticas sucessivas. (CLG, p. 250)

E Saussure leva o aparente paradoxo ainda mais longe:

É tão interessante saber como Messieurs! [Senhores!] repetido várias vezes seguidas num discurso é idêntico a si mesmo quanto saber por que pas (negação) é idêntico a pas (substantivo) ou, o que equivale ao mesmo, por que chaud é idêntico a calidum (ibid.).

O duplo "ponto de vista" adotado por Saussure a propósito da relação entre calidum e chaud-absolutamente diferentes, como é dito acima? Ou totalmente idênticos, como se acaba de ver? - parece de fato cair em contradição. Mas isso não acontece. Tendo como base a "escorregadia substância" que é a língua, Saussure procede a idas e vindas que assumem às vezes a aparência de contradição. Isso acontece porque os objetos a descrever são, por definição, "duplos". Sua duplicidade tem como alvo a copresença de dois fenômenos: a identidade diacrônica de calidum e de chaud, por um lado; e, por outro, a sequência, determinada "ao acaso" ou pela "fortuidade" dos acidentes fonéticos exteriores à língua que lhe conferiram um "aspecto" diferente. Esse "aspecto" nada tem que ver com sua identidade fundamental.

\footnotetext{
Saussure por vezes substitui o costumeiro acaso por esse belo neologismo para falar do regime, segundo ele estritamente aleatório, das "mudanças de sons" que se observam no "estado material dos signos" (2002, p. 215).
} 
Por fim, como se vê, há permanência na língua. Sem dúvida, a própria língua é, em sua essência, permanente. Seria necessário, para dar uma opinião inteiramente autorizada sobre as posições defendidas por Saussure sobre esse ponto, examinar em todos os detalhes a reflexão sem cessar inquieta com que ele o aborda. Por exemplo, reformular, seguindo seus passos, o problema da origem da linguagem e das línguas: lembremos que, para ele, "não se trata, na verdade, de uma questão a formular" ( $C L G$, p. 105). Examinar com atenção a distinção, flutuante, que ele estabelece entre "mudança fonética" e "mudança analógica". E reler a bela metáfora do "vestido recoberto de remendos feitos com seu próprio tecido" (CLG, p. 235). Ela marca a permanência da língua: é sempre o mesmo vestido, pois "depois de alguns séculos, quase todos os elementos são conservados" (ibid.). O tecido, sem dúvida a substância material do tecido, desempenha seu papel nessa conservação. É que de fato há necessidade de uma substância para manifestar constantemente a forma que a língua não cessa de ser.

\section{$* * *$}

Como vemos, ou ao menos eu o espero, a concepção de Saussure da imanência em termos da linguagem costuma dar forma à de Hjelmslev. Ela não deixa de distinguir-se desta, e com intensidade, em vários pontos. Com rigor mais decisivo, Hjelmslev não hesita em excluir, "provisoriamente", como ele mesmo precisa, tudo o que se refere, de acordo com ele, à "transcendência". Saussure vê a linguagem, "dupla por essência", como um objeto inevitavelmente "escorregadio". A metáfora pode ser considerada em vários sentidos. Escolho seu sentido literal: a linguagem nos escapa a todo instante em razão da própria multiplicidade dos pontos de vista, igualmente legítimos embora aparentemente opostos, dos quais é possível observá-la. A imanência é sem dúvida constante na definição da língua como sistema de valores. Mas sua estreita relação com o "sujeito falante" - excluída por Hjelmslev - diz respeito a outro ponto de vista. Transcendental? Talvez não. Mas seguramente não imanente.

Sobre essas insondáveis dificuldades, não creio encontrar melhor meio, para concluir, que dar a palavra ao Saussure de Science du langage:

Cada fato de linguagem [...] comporta não UMA, mas regularmente DUAS EXPRESSÕES RACIONAIS, ambas legítimas, uma tão impossível de suprimir como a outra, mas que equivalem a fazer da mesma coisa duas coisas distintas; isso sem nenhum jogo de palavras ou mal-entendido acerca do que acabamos de chamar uma coisa, ou seja, um objeto de pensamento distinto, e não uma ideia diversa do mesmo objeto. (2011, p. 67)

\section{Referências $^{8}$}

ENGLER, Rudolf. (1968). Édition critique du Cours de linguistique générale. Wiesbaden: Otto Harrassowitz, 1989. Tome I.

GODEL, Robert. Les sources manuscrites du Cours de linguistique générale de Ferdinand de Saussure. Genève: Droz, 1957.

HJELMSLEV, Louis. Le langage. Paris: Les éditions de Minuit, 1966.

HJELMSLEV, Louis. Prolégomènes à une théorie du langage. Paris: Les éditions de Minuit, 1971.

HJELMSLEV, Louis. Omkring Sprogteoriens Grundlaggelse, Copenhagen: The linguistic circle of Copenhagen, 1993. L'édition originale date de 1943.

MARINETTI, Anna; MELI, Marcello. Ferdinand de Saussure: le leggende germaniche. Este (Padova): Zielo, 1986.

SAUSSURE, Ferdinand de. (1916). Cours de linguistique générale. Paris: Payot (référencé dans l'article par l'abréviation $C L G), 1986$.

SAUSSURE, Ferdinand de. Écrits de linguistique générale. Paris: Gallimard, 2002.

SAUSSURE, Ferdinand de. Science du langage. De la double essence du langage. Édition des Écrits de linguistique générale établie par René Amacker, 2011.

SOFIA, Estanislao. Collation Sechehaye du Cours de linguistique générale, 1913. Limoges: Lambert-Lucas (à paraître), 2014.

SPINOZA, Baruch de. Pensées métaphysiques. In: Euvres complètes. Paris: Gallimard, Bibliothèque de la Pléiade, 1954. p. 300-356.

Recebido: 22 de maio de 2014

Aprovado: 30 de maio de 2014

Contato: michel.arrive@wanadoo.fr adail.sobral@gmail.com

\footnotetext{
8 Atendo-me a uma leitura que se quis literal dos textos, preferi citar só os elencados (NA).
} 